\title{
Por una sociología del espacio editorial: el caso de César Aira y Beatriz Viterbo
}

\author{
For a Sociology of the Publishing World: \\ the Case of César Aira and Beatriz Viterbo \\ Por uma sociologia do espaço editorial: \\ o caso de César Aira e Beatriz Viterbo \\ María Belén Riveiro*
}

\section{Resumen}

Este artículo adopta la mirada de la sociología de la literatura y parte de estudiar la trayectoria de César Aira con la hipótesis de que es en los años noventa cuando se puede identificar su creciente consagración. Uno de los indicadores para ello es una presencia simultánea en espacios que se definen como lógicas opuestas: la academia y el mercado editorial. Una de las editoriales que se convierte en un espacio clave para Aira es Beatriz Viterbo, creada en 1991 por tres académicas de la Universidad de Rosario. En este artículo, me centro en la editorial Beatriz Viterbo para analizar, a partir de datos recabados con entrevistas en profundidad y trabajo de archivo, las condiciones de posibilidad de la creación de una editorial que, desde la universidad, pero de manera independiente a la institución, fomenta una manera autogestiva y resistente a los modos dominantes de producción editorial, y que habilita trayectorias editoriales atípicas como la de Aira.

Palabras-clave: campo editorial, literatura argentina, sociología de la literatura, academia.

Abstract

This article takes the study of the trajectory of César Aira, whose growing consecration I identify during the 90s, to find one of the indicators of this recognition is Aira's simultaneous presence in spaces that follow, apparently, opposite logics: the academy and the publishing market. One of the publishing houses that is key to the trajectory of Aira is Beatriz Viterbo, founded in 1991 by three professors of the University of Rosario. This article focuses on the publishing house Beatriz Viterbo to analyze, from a sociological point of view and with the data collected through in-depth interviews and archival work, the conditions of possibility of this enterprise, which, linked to the university but in an independent manner, implements innovative ways of publishing resistant to the dominant ways of producing in the publishing field, which enables atypical publishing trajectories such as the one that Aira has developed.

Keywords: publishing field, Argentina literature, sociology of literature, academy.

\section{Resumo}

Este artigo adota a perspectiva da sociologia da literatura e parte do estudo da carreira de César Aira com a hipótese de que é nos anos 1990 que se registra sua crescente consagração. Um dos indicadores para isso é a presença simultânea em espaços definidos por lógicas opostas: a academia e o mercado editorial. Uma das editoras que se tornou um espaço essencial para Aira é a editora Beatriz Viterbo, criada em 1991 por três acadêmicos da Universidade de Rosário. Neste artigo, a partir de dados coletados em entrevistas detalhadas e arquivos, analiso as condições de criação de uma editora que, a partir da universidade, mas independentemente da instituição, promove a autogestão e a resistência aos modos dominantes de produção editorial, permitindo o desenvolvimento de trajetórias editoriais atípicas como a de Aira.

Palavras-chave: campo editorial, literatura argentina, sociologia da literatura, academia.

\footnotetext{
"Universidad de Buenos Aires, Buenos Aires, Argentina. Dorcid.org/0000-0002-0499-9320. E-mail: mariabelenriveiro@gmail.com
} 


\section{Entre el mercado y la academia}

En este artículo propongo pensar las condiciones de posibilidad de una trayectoria editorial peculiar como la de César Aira. Aira es un escritor argentino nacido en 1949 en Coronel Pringles, al sur de la provincia de Buenos Aires, quien desde 1981 publica ensayos, obras de teatro y, en su mayoría, novelas. En 2018 su obra llegó a superar los cien títulos. Hacia fines de la década de los años noventa y comienzos del siglo XXI rastreo indicadores convencionales de prestigio, como el hecho de que cuenta con numerosos premios, es un autor muy traducido, ocupa un lugar central en editoriales y su propuesta tiene una amplia recepción en la academia y en publicaciones periódicas como revistas literarias y suplementos culturales de diarios.

Esta trayectoria exitosa no está exenta de fricciones y resistencias. Una de las tensiones se da por el ritmo de publicación de Aira: "publica todo, indiscriminadamente: las novelas buenas y también las malas (las dudosas, las tontas)" (Contreras, 2003, p. 133). En lugar de emitir una valoración sobre esta práctica, me propongo preguntarme por sus condiciones de posibilidad y uno de los modos para comenzar a aprehender esta proliferación, sostengo, es concentrarse en una de las editoriales fundada, justamente, con un libro de Aira (Copi, 1991) y que, además, cuenta con 21 libros suyos en su catálogo (sin contar los libros traducidos por él), como Beatriz Viterbo editora. El estudio de este caso nos permite, por un lado, comenzar a indagar los vínculos entre las editoriales y los escritores ${ }^{1} \mathrm{y}$, en particular, las condiciones del campo editorial que habilitan una práctica editorial excéntrica como la de Aira; y, por el otro, explorar formas "de resistencia" -tomaré esta categoría nativa de las editoras Astutti y Contreras (2001) para convertirla en una categoría analítica- frente a las prácticas instauradas en numerosos sectores del campo editorial. ${ }^{2}$

Este estudio también nos permitirá problematizar ciertos sentidos cristalizados en torno a la figura de Aira. La proliferación de sus libros no siempre se entiende como una multiplicada presencia suya en el espacio público. "Soy extraordinariamente silencioso" afirma Aira en 1991 (Aira, 1991, p. 3). En contraste con la participación de Aira en diversas instancias como presentaciones de libros, ferias, publicaciones periódicas y entrevistas en los años ochenta, ${ }^{3}$ la figura del escritor oculto que es esquivo a las intervenciones públicas como entrevistas en medios de comunicación se instala de manera fuerte en relación con Aira desde los años noventa. Y se lee toda su trayectoria, de manera retrospectiva, a partir de ella. Tanto es así, que la revista 3 puntos anuncia una entrevista a Aira como un caso excepcional, en el cual para conseguirla "hay que hacer 13.000 kilómetros" (Aira, 2001a, p. 62) dado que se realiza en Francia con motivo de la presentación de la traducción de Un episodio en la vida del pintor viajero. ${ }^{4}$ Lo declaran haciendo caso omiso a la reciente primicia de Noticias que en agosto de 2001 publica una entrevista a Aira y también afirma: "Por primera vez en diez años, César Aira se deja entrevistar" (Aira, 2001b, p. 51).

Efectivamente encuentro que en 1994 Aira deja de dar entrevistas en medios de comunicación de Argentina. Sin embargo, la reticencia frente a las entrevistas no se traduce en un mutismo por parte del escritor. Frente a este silencio, Aira multiplica su presencia en dos espacios que se presentan con lógicas polarizadas dentro del campo literario: el mercado editorial y la academia. Hay otros casos en los que es clara la lógica excluyente de estos espacios, como el caso de otro escritor argentino contemporáneo a Aira, que ilustra estas lógicas contrapuestas. Me refiero a Jorge Asís, quien, en los años ochenta, no pasa desapercibido en tanto sus libros se convierten en

\footnotetext{
${ }^{1}$ En otro artículo estudio diversas trayectorias editoriales de escritores argentinos en las décadas de los años ochenta, noventa y la primera década del siglo XXI para dar cuenta de cómo se vinculan con distintas zonas del campo editorial. Véase Riveiro (2018).

${ }^{2}$ Este trabajo se inscribe en mi tesis doctoral donde reconstruyo la trayectoria de Aira entre 1981 y 2001 y donde propongo que Aira constituye un centro descentrado del campo literario de la ciudad de Buenos Aires (Riveiro, 2020).

${ }^{3}$ Estudio estas prácticas en Riveiro (2019).

${ }^{4}$ Las citas que reproducen esta imagen son numerosas. Cito algunas de ellas: "Desde hace años, Aira (Pringles, 1949), autor de más de sesenta libros entre novelitas, teatro y ensayos, no concede entrevistas en su país" (El país, 2004); "De pasada, César explica por qué no da entrevistas en su país" (La nación, 2005); "En pocas ocasiones accede a otorgar entrevistas -nunca en su país y casi nunca en el extranjero" (Bomb, 2009) se agrega a modo de presentación en la versión traducida al inglés de una entrevista realizada por María Moreno; "Hace dos décadas que el autor de La liebre no da entrevistas en Argentina, por lo que conversar con él es siempre una oportunidad celebrada" (Infobae, 2017).
} 
exitosos best sellers, mientras que esto no se traduce en un reconocimiento por parte de sus pares o de la crítica. En la revisión bibliográfica que realizo de publicaciones periódicas, que describiré en el subtítulo referido a la metodología, encuentro numerosas menciones a su literatura, así como entrevistas y reseñas a sus libros. Hasta Jorge Luis Borges, conocido por no dar su opinión sobre sus contemporáneos -"Mi literatura no tendrá herederos" dijo en el teatro Auditorium de Mar del Plata (Borges..., 1983, p. 24)- opina "yo tengo la convicción de que la mayoría de los escritores son muy superiores a mí [...] Ahora, desde luego, creo que puedo ser superior a un señor que se llame Asís, por ejemplo" (Borges, 1982, p. 3). En la literatura de Asís y en su figura (no es la única) se resalta la dimensión mercantil de la literatura porque Asís es un best seller. Pero a este éxito se le contraponen las constantes críticas que denostan esa literatura por ser caracterizada como de pobre calidad: el hecho de ser best seller no es valorado. A diferencia de los años sesenta, cuando esto se puede leer como un acercamiento del escritor con el público general, es decir, como un hecho deseable, en la época referida, cuando la dimensión mercantil asoma a la superficie va en detrimento de lo literario. ${ }^{5}$

La literatura de Aira, a la vez que copa el mercado editorial (como veremos en el tercer apartado), se convierte en objeto de la crítica universitaria en los años noventa. Los textos de universitarios y académicos dedicados exclusivamente a su obra literaria y figura comienzan a multiplicarse desde los años noventa. ${ }^{6}$ Además, los espacios universitarios se convierten en posibilidades de publicación de sus textos, especies de guías o marcos con los que leerlo. ${ }^{7}$ Aira publica en revistas académicas y universitarias como Paradoxa. Literatura/Filosofía (Aira, 1991a; 1993a), Boletín. Grupo de estudios de Teoría Literaria (Aira, 1993b; 1994a; 2001a), Tokonoma. Traducción y literatura (Aira, 1994b; 1995), Criterion (Aira, 1994c), El banquete (revista anual de literatura) (Aira, 1997) y Tigre. Travaux des hispanistes de l'Université Stendha (Aira, 1999).

Al indagar de manera más exhaustiva el estado del arte para el estudio de la obra de Aira encuentro una profusión de textos académicos publicados en Rosario. A esto se suma que en esas publicaciones también escribe Aira y, a la vez, es allí donde se editan gran parte de sus libros en esa década. Por ello, en este artículo me concentro en el caso de la editorial Beatriz Viterbo: allí se entrecruzan especialmente las dimensiones editoriales y académicas que son vitales para la trayectoria de Aira. Esta editorial la fundan en 1991 en Rosario Adriana Astutti, Sandra Contreras y Marcela Zanin, por aquel entonces recientes egresadas de la carrera de Letras de la Facultad de Humanidades y Artes de la Universidad de Rosario que comienzan a trabajar como docentes e investigadoras de esa casa de estudios. Astutti y Contreras, al reflexionar sobre su labor editorial años después, se inscriben en la tradición de "la imagen del editor tradicional" (2001, p. 771) dado que es "una imagen bisagra entre la tarea editorial y la enseñanza universitaria" (2001, p. 772). ${ }^{8}$

\footnotetext{
${ }^{5}$ Tendrán que pasar décadas para que ciertas zonas de la academia comiencen a valorar la literatura de Asís. A principios del siglo XXI Josefina Ludmer rescata la figura de Asís como "maldito" porque "está excluido, no aparece en los lugares donde los escritores quieren aparecer. No se sabe si escribe bien o mal" (citado en Moreno, 2011).

${ }^{6}$ Menciono algunos de estos trabajos: el artículo de Astutti (1997); el artículo de Montaldo donde lo compara con Jorge Luis Borges (1998) -ya en 1990 Montaldo publica un artículo en el que escoge a Aira entre otros escritores para estudiar la literatura argentina de la década anterior (1990); el libro de Estrín (1999); la tesis doctoral de Margarita Remon-Raillard (1999); el libro de Fernández (2000) y su posterior tesis doctoral (2005); el artículo que se propone desafiar las categorías convencionales de la crítica para abordar la obra de Aira escrito por Speranza (2001); la tesis doctoral de Contreras (2002); el artículo de Laddaga (2001); y los textos de Mattoni (2003) y de García (2006).

${ }^{7}$ Cabe aclarar que, de manera creciente, desde fines de los ochenta, Aira participa en espacios que dependen de la universidad. Participa de manera asidua en la Universidad de Buenos Aires. En 1984, en el ciclo Conversaciones en Puan donde conversa con Rodolfo Fogwill. En 1986, en el encuentro Los que conocieron a Osvaldo Lamborghini, en 1988 dicta un curso sobre Copi, en 1992 da charlas sobre Rimbaud y en 1996, sobre Alejandra Pizarnik, todo ello en el Centro Cultural Ricardo Rojas, que depende de la Universidad de Buenos Aires.

8 "Somos profesoras de Literatura Argentina en la Universidad Nacional de Rosario y, a decir verdad, lo que nos movió en ese momento (al final de una jornada de estudio de la Teoría Estética de Adorno donde se mostraba el equilibrio precario de la autonomía del arte frente a la industria cultural) fue la idea, y el deseo, de generar un espacio en el que pudiéramos ampliar el horizonte de nuestra profesión sin dejar nuestro país ni nuestra ciudad (la ocurrencia y el deseo de ser editor: sin duda los mismos móviles que animan al surgimiento de tantas pequeñas editoriales) [...] Naturalmente, entonces, nuestro catálogo se ha ido definiendo a partir del entrecruzamiento de esos dos oficios: el de profesor y el de editor" (Astutti y Contreras, 2001, p. 772).
} 
Beatriz Viterbo es una editorial creada con capitales nacionales y que cuenta con una estructura pequeña (funciona con el trabajo de sus tres fundadoras). Por ello puede entenderse dentro de la zona de las editoriales independientes. ${ }^{9}$ El foco de este artículo no está en la discusión y análisis de la categoría de independiente ${ }^{10}$ porque el objetivo es dar cuenta de las condiciones de posibilidad de un proyecto como el de Beatriz Viterbo así como sobre los efectos que tienen este tipo de editoriales en las trayectorias de los escritores y los modos novedosos de producción editorial que suponen.

A continuación, parto por describir las principales categorías teóricas implementadas y la metodología seguida. Luego, analizo la trayectoria editorial de Aira sobre todo a partir de los años noventa, dado que Beatriz Viterbo editora es clave para habilitar esa práctica. Por último, paso al análisis de la editorial Beatriz Viterbo: reconstruyo el estado del campo editorial en el que surgen numerosas editoriales de capitales nacionales y con infraestructuras pequeñas como Beatriz Viterbo, y estudio los capitales sociales puestos en juego y los conocimientos involucrados para su creación, así como los efectos innovadores y resistentes a los modos hegemónicos de editarla y su propuesta particular que caracterizaré de heterodoxa.

\section{Teoría y metodología}

El presente artículo se inscribe en la sociología de la literatura y del espacio editorial y en la propuesta de Pierre Bourdieu (2007) que propone dar cuenta de las mediaciones sociales que enriquecen nuestro conocimiento sobre objetos del arte y la literatura. Conceptualizo a la literatura y a la práctica editorial como prácticas sociales que, como toda práctica, construyen y también reciben condicionamientos.

En una esclarecedora introducción a la teoría de la acción de Bourdieu, Loïc Wacquant (1995) esquematiza dos momentos del análisis. Por un lado, un alejamiento de las representaciones cotidianas para construir un espacio de posiciones y recursos que definen coerciones externas y límites: el campo. Y, por el otro, la reintroducción de la experiencia de los agentes, de sus categorías de apreciación y percepción, en otros términos, sus tomas de posición: sus disposiciones (Bourdieu y Wacquant, 1995, p. 20). Wacquant entiende que, escapando de los binarismos, la apuesta de Bourdieu es por el estudio de la relación de complicidad ontológica entre el agente social y el mundo. El foco no está en ninguno de los términos sino en las relaciones.

Una de las principales categorías en este artículo es la de la trayectoria. Se define como "la serie de las posiciones sucesivamente ocupadas por un mismo agente o un mismo grupo de agentes en espacios sucesivos" (Bourdieu, 2005, p. 384). Es "una manera singular de recorrer el espacio social, donde se expresan las disposiciones del habitus" (Bourdieu, 2005, p. 384). El estudio de la trayectoria de un actor busca evitar la reconstrucción de un proyecto originario que integre toda la verdad objetiva de una condición, de una historia, de una biografía y de una obra y que defina la imagen inaprehensible del genio o del carisma. La pregunta es por las condiciones de producción de esa singularidad. En este artículo parto de la trayectoria de Aira para concentrarme en la dimensión de su práctica editorial, en particular, en lo que respecta a su vínculo con la editorial Beatriz Viterbo.

Estudiar la relación de la literatura con dimensiones de lo social supone incorporar mediaciones. Una de las instancias que media entre lo literario y lo social es el campo editorial. La producción editorial también aparece como "espacio social relativamente autónomo -es decir, capaz de

\footnotetext{
${ }^{9}$ De hecho, en el año 2000 la editorial Beatriz Viterbo es identificada como una editorial independiente al ser invitada al Primer Encuentro de Editores Independientes de América Latina. en el marco del III Salón del Libro Iberoamericano de Gijón-España. Dos de sus editoras, Contreras y Astutti, reflexionan sobre la categoría (2001). Las editoras proponen, en discusión con la categoría de independiente, pensar en la noción de "editoriales pequeñas" (Astutti y Contreras, 2001, p. 768) que evita el binomio buena calidad-mala calidad, en tanto ello - proponen- depende de su catálogo. Distinguen a las editoriales de acuerdo con el tamaño de su estructura y la tirada de sus libros y sobre todo de acuerdo a "una suerte de micropolítica cultural, si entendemos por micropolítica la creación de espacios transversales en el medio de los espacios que distribuyen e imponen las políticas mayores" (Astutti y Contreras, 2001, p. 773).

${ }^{10}$ Existe profusa bibliografía acerca de los debates de los sentidos sobre el adjetivo de independiente y sobre los modos de conceptualizar a estas editoriales. Véase, Vanoli (2009, 2010), Saferstein y Szpilbarg (2012) y de Souza Muniz Júnior (2015).
} 
retraducir, según su propia lógica, todas las fuerzas externas, económicas y políticas, especialmenteen el cual las estrategias editoriales encuentran su principio" (Bourdieu, 2000, p. 229 y 230).

Cabe aclarar que sigo a Ana Teresa Martínez cuando propone un particular vínculo con la teoría guiado para "detectar virtualidades en los bordes disponibles de las nociones abiertas que constituyen su teoría del mundo social" (2007, p. 22). Martínez destaca el carácter operativo de las nociones teóricas y encuentra una gran productividad en la teoría de Bourdieu, a cuyo estudio se aboca para recorrer y reconstruir el proceso de elaboración de sus interrogantes y respuestas en relación con los diálogos y debates de los que participa, para aplicarla a diversos casos dado que hipotetiza que la preocupación por evitar el etnocentrismo recorre toda su obra. Partimos de la necesidad de la reinvención de cada teoría en función de cada caso concreto (Martínez, 2007, p. 277).

En el caso de este artículo es clara esta reformulación cuando pienso los vínculos entre academia y mercado. El caso de Aira y su trayectoria editorial y vínculo con la editorial Beatriz Viterbo nos permite desafiar y repensar la relación entre lógicas que se plantean como opuestas. Cuando Bourdieu estudia la conformación del campo literario como un "universo relativamente autónomo", encuentra allí "una economía al revés, basada en su lógica específica, en la naturaleza misma de los bienes simbólicos, realidades de doble faceta, mercancías y significaciones, cuyos valores propiamente simbólico y comercial permanecen relativamente independientes" (2005, p. 213). En relación con el campo editorial específicamente encuentra un polo heterónomo, "para los editores y los escritores orientados hacia la venta, y para su público, el éxito es por sí mismo, una garantía de valor. Eso es lo que hace que, en el mercado, el éxito conduzca al éxito: se contribuye a fabricar bestsellers publicando sus tiradas" (Bourdieu, 2005, p. 223), y otro polo, opuesto, para el cual "el éxito inmediato resulta algo sospechoso" (Bourdieu, 2005, p. 224), "convierte la ascesis en este mundo en la condición de la salvación en el más allá" basado en "la lógica específica de la alquimia simbólica, que exige que sólo sean recuperables las inversiones que son (o parecen) a fondo perdido" (Bourdieu, 2005, p. 224). El caso de este artículo, la trayectoria editorial atípica de Aira y las habilitaciones que supone Beatriz Viterbo como puente entre el mercado editorial y la academia, me permite repensar los vínculos entre polos que parecieran opuestos y alejados en el espacio.

Antes de pasar a detallar la metodología implementada cabe aclarar una cuestión relativa al modo en que conceptualizo el caso empírico. Estudiar a Aira y a la editorial Beatriz Viterbo, desde una mirada sociológica, me permite indagar en hechos que desbordan sus individualidades, como el caso de este artículo en el que indago en el campo editorial de los años noventa. Por ello preciso diferenciar a los individuos empíricos de los individuos científicamente construidos (Martínez, 2007). En este trabajo, cuando menciono la trayectoria de Aira, así como cuando lo hago con diversos editores, me refiero a un caso particular dentro del universo de lo posible, una singularidad que no constituye una probabilidad calculable sino una posibilidad razonable. Los nombres propios en tanto individuos construidos en la investigación:

ya no deben ser aquí leídos como etiquetas que señalan seres humanos concretos, en la riqueza de la totalidad de su vida histórica, sino palabras para nombrar un conjunto limitado de propiedades seleccionadas según las necesidades de la investigación, y explícitamente definidas y convertidas en variables, variables que adquieren su valor en el sistema correspondiente de diferencias, y obtienen su significación del conjunto de relaciones explícitamente definidas, cuyos nudos están representados por esas palabras (Martínez, 2007, p. 243).

Identificar la participación de Aira en publicaciones académicas y universitarias en los años noventa en contraste con los años ochenta, y encontrar que en 1994 deja de dar entrevistas hasta 2001 en medios de comunicación de Buenos Aires, aunque sí sea posible hallar entrevistas en los ochenta, es posible por el trabajo de archivo que realizo. Para la revisión documental confecciono un corpus de publicaciones periódicas con libros y artículos que funcionan como catálogos de publicaciones argentinas dedicadas a la literatura: el estudio sobre revistas literarias de José M. Otero publicado en 1990 por Catedral al Sur editores, 30 años de revistas literarias argentinas (1960-1989). Introducción a su estudio; el trabajo también hemerográfico de Nélida Salvador, Miryam Gover de Nasatsky y Elena Ardissone publicado en 1996 por la Fundación Inca seguros, Revistas literarias argentinas, 1960-1990. Aporte para una bibliografía; el 
informe final de Claudia Román (1997) que analiza un conjunto de revistas literarias que define como relevantes para los años de la transición democrática, Revistas literarias de Buenos Aires en los años de la democracia (1983-1993); el estudio sobre el denominado periodismo cultural de Pablo Chacón y de Jorge Fondebrider de 1998 publicado por Colihue, La paja en el ojo ajeno. Periodismo cultural argentino (1983-1998); el catálogo de revistas del acervo del Centro de documentación e investigación de la cultura de izquierdas (CeDInCI) confeccionado por su director, Horacio Tarcus en 2007, Catálogo de revistas culturales argentinas. 1890-2007; y el artículo de Sebastián Hernaiz de 2012 sobre revistas de los años noventa, "Revistas literarias y lugar social de la literatura en los '90", compilado en Rodolfo Walsh no escribió Operación Masacre y otros ensayos de la editorial 17 grises.

La lectura de publicaciones de Rosario no constituye una tarea como la realizada para las publicaciones de Buenos Aires. En el caso de Rosario los criterios son teóricos: consulto sólo las publicaciones del grupo de intelectuales que estudian a Aira y aquellas que ellos me recomiendan cuando los entrevisto. En Rosario consulto publicaciones en la Biblioteca Central de la Facultad de Humanidades y Artes de la Universidad de Rosario, en la Biblioteca de la Escuela de Letras de esa misma casa de estudios.

Identificar la práctica editorial de Aira no resulta sencillo dada su proliferación y sus particulares características, como veremos más adelante. La obra de Aira, que en 2018 supera los 100 libros y que se encuentra editada en diferentes países de América Latina, así como en España, resulta a primera instancia difícil de asir. Las primeras ediciones, sobre todo de los primeros libros que publica Aira, son difíciles de hallar y, a medida que se afianza su consagración comienza a surgir la práctica del coleccionismo, por lo que cotizan de otra manera. Ricardo Strafacce, a quien Aira conoce cuando el primero investiga sobre la vida de Osvaldo Lamborghini para la biografía que publica en 2008, cuenta con la obra completa, y en primeras ediciones. Me permitió acceder a su biblioteca por lo que pude contar con esa obra. ${ }^{11}$

La revisión bibliográfica sobre el mundo editorial argentino resulta vital. Contamos con un corpus profuso de investigaciones sobre el campo editorial argentino que retomaré en el desarrollo del artículo de manera oportuna. A su vez, es posible consultar investigaciones sobre editoriales universitarias en particular de Argentina y América Latina (Sagastizábal, 2002; Sagastizábal, Rama y Uribe, 2006; Aguilar, 2012; Centeno, 2012; Costa y Gazzera, 2013; Sagastizábal y Vega, 2013; Costa y de Sagastizábal, 2016; Mihal y Szpilbarg, 2018; Dujovne, 2020). En el desarrollo del artículo detallaré las particularidades de Beatriz Viterbo, que tiene lazos, sin lugar a dudas, con la universidad, pero que no es la editorial institucional de ese organismo académico.

Esta información la complemento al realizar entrevistas en profundidad. Realizo entrevistas a Alberto Giordano, ${ }^{12}$ Sandra Contreras, ${ }^{13}$ Nora Avaro ${ }^{14}$ y Marcela Zanin ${ }^{15}$ en Rosario a fin de recabar datos y reconstruir experiencias y climas que no quedan registrados en documentos escritos. Estas conversaciones son vitales por los datos referidos a la trayectoria de Aira y a la editorial Beatriz Viterbo, pero también sobre el panorama literario de cada momento específico. Por lo tanto, actúan como entrevistados y como informantes clave. El trabajo con el material de las entrevistas es central no solo como fuente de información y guía para la búsqueda documental sino como instancia necesaria para el estudio del objeto de este artículo. La mirada que adopto es crítica con respecto al material y las fuentes documentales, pero no supone automáticamente negar los conocimientos de los actores sino incorporarlos dado que su "certeza subjetiva forma parte también del hecho social" (Martínez, 2007, p. 67).

\footnotetext{
${ }^{11}$ Este trabajo junto con el trabajo de archivo mencionado me lleva a participar en la confección de anexos del libro que publica Strafacce por Mansalva en 2018, César Aira, un catálogo, en el que enlista y selecciona una página de cada uno de los libros de Aira. En los anexos del libro detallo los textos de Aira que salen en publicaciones periódicas.

${ }^{12}$ Entrevista realizada los días 24 y 25 de julio de 2019.

${ }^{13}$ Entrevista realizada el 22 de julio de 2019.

${ }^{14}$ Entrevista realizada el 25 de julio de 2019.

${ }^{15}$ Entrevista realizada el 23 de julio de 2019.
} 
El recorte temporal de este trabajo de archivo y del artículo abre en 1991 (año de creación de la editorial Beatriz Viterbo, fundada con el libro Copi de Aira) y cierra en 2001. En este año identifico indicadores de una creciente consagración del escritor tales como los mencionados en la introducción, así como dos datos específicamente relevantes para este artículo. En 2001 Contreras defiende su tesis doctoral en la Universidad de Buenos Aires, dedicada exclusivamente a la obra de Aira. ${ }^{16}$ En 2001 también es posible identificar un rasgo llamativo de la trayectoria editorial de Aira: publica, como diez años antes, un libro en Beatriz Viterbo (Las tres fechas) y, a la vez y en el polo opuesto del campo editorial -como veremos-, participa de los tres grandes grupos editores transnacionales: el grupo Planeta que en 2000 compra Emecé ( $L a$ villa, 2001), Random House Mondadori que en 2001 firma la unión que crea este conglomerado (Cumpleaños, 2001) y el grupo Santillana que en 1980 compra Alfaguara y se va expandiendo, y que posee las editoriales Aguilar, Altea, Taurus y opera en más de 20 países, hasta que en 2000 incluso compra las librerías Fausto que incluyen las cadenas El Ateneo y Yenny (Un sueño realizado, 2001). El recorte espacial lo componen Rosario, donde se funda Beatriz Viterbo, y la ciudad de Buenos Aires porque allí reside Aira y es donde comienza a publicar libros y artículos. Allí también identifico reseñas de su obra. Las publicaciones periódicas que conforman el corpus mencionado son aquellas publicadas en Buenos Aires y Rosario.

\section{La trayectoria editorial de César Aira}

"César Aira no tiene paz [...] parece encerrar mil personas que escriben a la vez" anuncia Los Inrockuptibles en relación con la publicación del Diccionario de autores latinoamericanos (Aira, 2001b). ${ }^{17}$ Entre 1991 y 2001 Aira publica 36 libros en 13 editoriales diferentes y en 6 ciudades.

El ritmo de publicación es acelerado. En 1991 publica cuatro libros; en 1992, tres; en 1993, cuatro; en 1994 tres; en 1995 y 1996 dos; en 1997, cuatro; en 1998, cinco; en 1999, uno; en 2000, dos; en 2001, cinco. La solapa de El juego de los mundos (2000) advierte: "Es un dato biográfico la aparición de tres o cuatro libros anuales que llevan su firma. El juego de los mundos cierra, en este caso, la extensa lista. Por poco tiempo".

No hay un solo género en que podamos clasificar estos libros. Hay novelas: ${ }^{18}$ El bautismo, $\mathrm{La}$ liebre, El llanto, El volante, Embalse, La prueba, Cómo me hice monja, La guerra de los gimnasios, La costurera y el viento, Los misterios de Rosario, La fuente, Los dos payasos, La abeja, Dante y Reina, El congreso de literatura, La serpiente, El sueño, La mendiga, Las curas milagrosas del Doctor Aira, El juego de los mundos, Un episodio en la vida del pintor viajero, La villa y Un sueño realizado. Relatos: El infinito, Taxol (precedido de Duchamp en México y La broma), La trompeta de mimbre y Haikus. Diarios: Diario de la hepatitis. Teatro: Madre e hijo, El mensajero. Y ensayos: Copi, Nouvelles impressions du Petit Maroc, Alejandra Pizarnik, Cumpleaños, Diccionario de autores latinoamericanos y Las tres fechas.

Las editoriales donde publica Aira también son heterogéneas. Como vimos antes, en 2001 Aira publica libros en los tres grandes grupos editores transnacionales: el grupo Planeta (La villa, 2001), Random House Mondadori (Cumpleaños, 2001) y el grupo Santillana (Un sueño realizado, 2001). En simultáneo publica en "microeditoriales" (Saferstein y Szpilbarg, 2012) o "pequeñas editoriales

\footnotetext{
${ }^{16}$ La tesis, La vuelta del relato en la literatura de César Aira en el contexto de la narrativa argentina contemporánea, es dirigida por Nicolás Rosa y defendida en 2001 en la Facultad de Filosofía y Letras frente a un jurado compuesto por Ana María Camblong, Beatriz Sarlo y Susana Zanetti. Este trabajo se centra exclusivamente en la obra de Aira y la plantea como una singularidad que tensiona una vocación de anacronismo y de ilegibilidad con una propuesta de lectura del futuro. Contreras publica la tesis en 2002 bajo el título de Las vueltas de César Aira en la editorial Beatriz Viterbo.

${ }^{17}$ Ariel Idez escribe una novela que titula La última de César Aira donde utiliza recursos de la obra de Aira además de que expone, ficcionalizada, una teoría sobre su figura y práctica de publicación. Aira publica con un ritmo acelerado porque en un túnel subterráneo que "era todo negros con sus computadoras sobre los escritorios" se escriben, imprimen, archivan y envían sus novelas (Idez 2011, p. 125). Tantas son las novelas que de publicarlas todas "provocaría una saturación por sobrecarga en el sistema simbólico, asestaría un golpe preciso y mortal a la literatura argentina que sostiene en secreto la ficción del país o el país ficción, y dejaría al descubierto la áspera piel de lo real, enfrentando al Desierto con su propia imagen" (Idez, 2011, p. 167). La novela termina cuando encuentran en un silo de Pringles "millones de novelas de César Aira" (Idez, 2011, p. 211). En ese paisaje "el crepúsculo acentuó sus tonos hasta más allá de un color. Hubo un fulgor rosado y un viento, como una brisa, que se desplegó veloz. Y la Argentina dejó de existir" (Idez, 2011, p. 211).

${ }^{18}$ Para esta clasificación sigo a Ricardo Strafacce que ordena los libros de Aira en César Aira, un catálogo (2018).
} 
literarias artesanales" (Vanoli y Saferstein, 2011) y en "editoriales medianas y pequeñas de capital local" (Saferstein y Szpilbarg, 2012). A modo de ejemplo, puedo citar El infinito que sale en una editorial que parece no tener más libros en su catálogo y que tiene, por ese entonces, el registro de propiedad intelectual en trámite: Vanagloria. Su circulación es más restringida que cualquier otra novela. Es de los pocos libros sobre los que no rastreo reseñas. También publica en otras pequeñas editoriales de capitales nacionales de reciente creación como Ada Korn (Buenos Aires, 1984), Bajo la luna (Rosario, 1991), Beatriz Viterbo (Rosario, 1991), Simurg (Buenos Aires, 1995), Mate (Buenos Aires, 1996) y El broche (La Plata, 1999).

No es posible identificar a Aira, en ningún momento de su trayectoria, con un editor en particular ni tampoco con un tipo de editorial. Hopenhayn recurre a la figura del marketing para reflexionar en 1998 sobre los modos en que Aira tiene una "doble vida editorial con la que parece sostener una política de sí mismo" (Hopenhayn, 1998, p. 7). En contraste con ello, "ninguna editorial ni medio de comunicación puede tentarlo tanto como para hacerle perder su autonomía" (Hopenhayn, 1998, p. 7). Aira parece nunca llegar a trazar el camino de "profesionalización" que sí recorre un escritor central en los ochenta como Juan José Saer, cuya consagración se funda, en parte, por este vínculo editorial (Dalmaroni, 2010). Saer, tras "esa modalidad errabunda" de publicación en editoriales diversas de los años sesenta, pasa a Alianza editorial y después a Seix Barral del Grupo Planeta porque entabla una relación sólida con el editor Alberto Díaz, quien comienza a trabajar en Seix Barral (Dalmaroni, 2010, p. 660). Díaz da "continuidad a un plan de publicación" (Dalmaroni, 2010, p. 661) y desarrolla una política editorial que incluye la planificación de entrevistas, políticas de prensa al momento de la edición de un libro, ediciones escolares de las novelas y la recopilación de las obras completas, entre otras prácticas (Dalmaroni, 2010).

La peculiaridad de la práctica editorial de Aira no pasa desapercibida ante los críticos y teóricos literarios. Sobre ello reflexiona Montaldo, quien estudia el vínculo entre la literatura de Aira y la industria cultural para proponer que su supervivencia es posible porque, frente a la literatura que acostumbran a editar "las editoriales multinacionales", Aira, "escritor ya prestigiado [...] publica en editoriales artesanales, marginales, de escasa circulación y escribe una literatura cada vez más ininteligible, por exceso de inteligibilidad" (1998, p. 14). Sobre la práctica editorial, Montaldo explica que "desde el margen editorial satura el mercado de textos marca Aira" (1998, p. 14). Contreras (2002) identifica que, desde comienzos de los años noventa, comienza a funcionar la "máquina" de producir "novelitas" a un ritmo de tres o hasta cinco novelas por año. Retoma el análisis de Montaldo de la "superproducción a-mercantil artesanal" (Montaldo, 1998, p. 14), que lee junto con la categoría del continuo de Aira, para definirlo como un fenómeno de publicación "indiscriminada" que se contrapone a valores dominantes identificados con la práctica del escritor signada por la clandestinidad y la lentitud. ${ }^{19}$

Daniel Link (2003) también se detiene en este fenómeno porque identifica que "si la literatura parece hoy 'cosa del pasado' no es por su incapacidad para dar cuenta del presente [...] sino por su debilidad para enfrentar la lógica (reificante) del mercado" (Link, 2003, p. 332). Frente a esta situación, la postura de los escritores es diferente: "Aira se lleva esa lógica por delante, Piglia (o Saer, o Fogwill) tropiezan con ella (y esos traspiés vuelven interesante la lectura y el análisis de sus textos). Tomás Eloy Martínez sencillamente cae en sus brazos" (Link, 2003, p. 332).

Lo que identifico con la descripción realizada en este apartado es una irrupción de Aira en los modos en que se publica, un ritmo acelerado de publicación y la participación en catálogos de editoriales de distintas características. Pero ¿es una práctica que Aira decide implementar en los noventa? Indicios de este modo de publicar se pueden rastrear desde sus primeros libros: Javier Vergara (que publica Canto Castrato, 1984, y Una novela china, 1987) es una editorial con sede en Buenos Aires y en el extranjero mientras que Ada Korn (que publica El vestido rosa y Las ovejas, 1984) es una editorial incipiente cuya fundadora se encarga de todas las tareas de la publicación.

\footnotetext{
${ }^{19}$ El paradigma del autor clandestino, escondido, que reserva su obra para la posteridad es Macedonio Fernández. Mientras que la construcción de la gran novela a lo largo del tiempo, tamizada por la crítica de Piglia, encuentra su punto alto en Los Sorias de Alberto Laiseca (Contreras, 2002). En contraste con esto, Aira "publica todo, indiscriminadamente: las novelas buenas y también las malas (las dudosas, las tontas)" (Contreras, 2002, p. 133), como cito antes.
} 
En una entrevista de 1987 Aira comenta: “Tengo varios [libros inéditos], lo que pasa es que hay tan pocos editores" (Aira, 1987, p. 2). Parece que a Aira no le alcanza con editoriales y decide publicar adelantos de novelas inéditas en publicaciones periódicas. Además de las novelas editadas y de las inéditas que circulan entre escritores y críticos, ${ }^{20}$ Aira publica fragmentos de otros libros en publicaciones periódicas: un texto sobre Girondo titulado "Había una vez" en Xul (1984), "El estúpido reflejo de la manzana en la ventana" en El porteño (1985), "Los aragoneses de Famatina" en Vuelta sudamericana (1987), y "Cecil Taylor" (1988), Fin de siglo, que en 1992 se incluirá en Una antología de nueva ficción argentina organizada por Juan Forn para Anagrama y que en 2011 sale como libro en Mansalva.

La pregunta que formulo es ¿cómo se dieron las condiciones para que Aira trace esta trayectoria y práctica editorial acelerada, que no se identifica con un solo editor ni con un solo tipo de editorial? Para responder este interrogante propongo indagar en el estado del campo editorial de los años noventa que es el mismo en el que se funda el caso en el que me enfoco: Beatriz Viterbo editora.

\section{Beatriz Viterbo editora}

\section{El campo editorial en los años noventa}

En los años noventa en Buenos Aires se consolidan procesos de transformación del campo editorial marcados por la concentración de empresas editoriales transnacionales ${ }^{21}$ y la emergencia, y posterior proliferación, de editoriales autodenominadas independientes (Botto, 2014). El valor rector de las editoriales que forman parte de los grupos transnacionales es el concepto de competitividad. Ello se traduce en tiradas reducidas, sucesivas reimpresiones, la aceleración de rotación de libros, la segmentación de la producción y la diversificación de la demanda. La valoración de la novedad va en detrimento de la conformación de un fondo editorial (Diego, 2010). La figura del editor también se transforma. De una figura ejemplar, patriarcal, apoyada en redes de relaciones interpersonales (reactivada con la superposición de roles: editor-lector-autor), de carácter político y regional, que une la dedicación al mundo editorial con el trabajo en la universidad, se pasa a un trabajo de tiempo completo que supone otros conocimientos relacionados con disciplinas como el marketing y otras relaciones, el trabajo con un comité editorial y el destino no a nivel regional sino a los mercados donde está inserto el grupo económico (Szpilbarg, 2019).

Los grupos transnacionales ocupan las posiciones dominantes del mercado editorial: controlan el 75\% de los ingresos del mercado en los años noventa y comienzos del siglo XXI (Szpilbarg, 2019). Pero mientras que explican la mayor parte de los ingresos del sector editorial, representan menos de la mitad de ese sector dado que desde la década de los años noventa, y con más fuerza a partir del siglo XXI, se identifica una proliferación de editoriales autodenominadas independientes (Vanoli y Saferstein, 2011, p. 79). La emergencia de editoriales "en una cantidad y

\footnotetext{
${ }^{20}$ En el primer número de El porteño (1982-1992), revista de la que Aira participará, se escribe sobre Ema, la cautiva (1981, Editorial de Belgrano) y numerosos otros títulos en una sección sin firma llamada Gato montés que anuncia noticias del mundo de la cultura. "De nadie se hablaba tanto en ciertos bares y en ciertas casas como del autor de Ema, o de La luz argentina o de Reflejos en la estúpida manzana o de El faisán-sultán, o de otras tantas 20 novelas inéditas que circulaban y aún circulan en codiciadas fotocopias" (Faisán-autor, 1982, p. 25). De hecho, llaman a Aira "el best-seller de los inéditos" (Faisán-autor, 1982, p. 25).

${ }^{21}$ En 1993 se dicta el decreto ${ }^{\circ} 1853 / 93$. Éste modifica la ley de inversiones extranjeras sancionada el 19 de agosto de 1976 . El decreto surge en medio de la implementación de las políticas neoliberales en consonancia con las "recomendaciones" del Banco Mundial. Por aquel instrumento se suprime el requisito de aprobación previa de inversiones foráneas destinadas, entre otros sectores, a "diarios, revistas y editoriales" (Azpiazu, Manzanelli y Schorr, 2011). El período de la convertibilidad es un proceso complejo que supone diversas dimensiones (Cantamutto y Wainer, 2013), una de ellas es la privatización de empresas estatales y una mayor intensidad de la inversión extranjera directa que configuran la extranjerización de la estructura económica. El mercado editorial no escapa a este clima. Además, desde la década de los ochenta, la tendencia internacional en el sector editorial es la creciente concentración empresarial (Fernández Moya, 2011; Szpilbarg, 2019). Una recopilación de las adquisiciones a nivel internacional de editoriales y entre grupos transnacionales (no sólo de empresas abocadas a la edición de libros sino también de librerías), se puede consultar en el trabajo "Concentración económica, nuevos editores, nuevos agentes" (Diego, 2012). Otro factor, que explica estos fenómenos y que desborda la lógica económica, parecer ser "la debilidad de algunas compañías familiares que no eran capaces de hacer frente con éxito al cambio generacional de la familia, y que facilitaron la venta de la compañía” (Fernández Moya, 2011, p. 25).
} 
a un ritmo que lleva a muchos establecer comparaciones -para bien y para mal- con otro momento de efervescencia editorial: los años sesenta" (Botto, 2014, p. 237 y 238) es contemporánea a este fenómeno de transnacionalización y concentración. Mientras que "la transnacionalización de la industria no tiene que ser entendida como una ruptura sino más bien como una continuidad con el modelo editorial sentado por las editoriales de la 'época de oro' (Emecé, Sudamericana, Losada)" porque el tipo de relación con la cultura literaria se mantiene (Vanoli y Saferstein, 2010, p. 78), surgen otros espacios que comienzan a problematizar ese vínculo. Son "emprendimientos de menor escala" autoidentificados como editoriales independientes que se fundan en el marco de las discusiones internacionales sobre la bibliodiversidad. ${ }^{22}$

Estas editoriales tienen una fuerte presencia en suplementos culturales y revistas literarias y especializadas (La Maga, Punto de Vista, $V$ de Vian, entre otras) y construyen circuitos alternativos. ${ }^{23}$ Tienen un margen de rentabilidad muchísimo menor. Los editores son, en su mayoría, lectores y escritores y la dimensión económica queda en segundo plano frente a la apuesta por "publicar a un autor desconocido, reflotar algún título ignoto, reeditar otro inhallable u ofrecer una nueva traducción" (Botto, 2014, p. 240). Se apuesta por un proyecto cultural sustentado en redes de sociabilidad que enfrentan la lógica reinante de la competencia. Estas editoriales hacen de la necesidad virtud: se especializan en ciertos temas y autores que "las empresas líderes descuidan por considerarlos demasiado riesgosos" (Botto, 2014, p. 241). Así se crea una cierta apertura hacia proyectos como el de Aira cuya proliferación, como vimos, llama la atención de los actores del campo. ${ }^{24}$

Algunas de estas son las editoriales Adriana Hidalgo editora (1999), Paradiso (1992), Bajo la luna (1992), Simurg (1995), y Siesta (1997). ${ }^{25}$ Otra de ellas es Beatriz Viterbo. ¿Cómo surge este proyecto que, como vimos, no será una excepción en el campo editorial de los noventa?

\section{Una posibilidad de resistencia y libertad}

Resistencia y libertad es lo que encuentran Astutti y Contreras (2001) cuando reflexionan sobre su rol como editoras. ¿Cómo construyen un espacio desde donde fomentar este tipo de práctica editorial? En ello están involucrados capitales sociales, conocimientos prácticos adquiridos en sus trayectorias laborales y educativas y una propuesta editorial heterodoxa.

En primer lugar, Astutti, Contreras y Zanin cuentan con cierto capital social que les provee de conocimiento y experiencia editorial. Cuando se proponen crear una editorial contactan a Susana Zanetti. Zanetti "en los momentos de rearticulación del campo de la literatura latinoamericana no dudó en armar las valijas [...] para ejercer la docencia en las Universidades de Rosario, Comahue, Mar del Plata, La Pampa, Salta, Córdoba" donde dicta cursos

\footnotetext{
${ }^{22}$ Véase el antecedente de Unesco Declaración Universal sobre la Diversidad Cultural de 2002; la producción de la Alianza Global para la Diversidad Cultural creada por la UNESCO en 2003, la Alianza de editores independientes por otra mundialización que en Argentina toma la forma del colectivo EDINAR (Alianza de Editores Independientes por la Bibliodiversidad).

${ }^{23}$ A modo de ilustración, editoriales sobre todo de poesía, se reúnen frente a la Feria del libro de Buenos Aires para organizar la Contraferia desde 1998. Arman un stand donde venden sus libros. Exigen que la entrada a la Feria sea gratuita y que les permitan ingresar y tener un lugar para sus propuestas editoriales. En 2001 la Secretaría de Cultura de la Nación dispone un espacio dentro de la Feria para 31 editoriales independientes (Bembibre, 1999; Buquete, 2001). Se trata de un antecedente clave de la Contraferia de 2006 que va a ser el germen de la Feria del Libro Independiente. Sobre ello, véase Szpilbarg (2019). En otros casos, las editoriales trabajan en conjunto para exportar su catálogo, de manera similar a la estrategia colaborativa que da origen a Los siete logos. Esta práctica se conceptualiza como "economía de favores" (Hutnik, 2013) o como "comunidad de favores" (Botto, 2014). Los Siete Logos incluye tanto a editoriales de los noventa (Bajo la luna y Adriana Hidalgo) como a otras creadas en el siglo XXI (Eterna Cadencia, Katz, Caja Negra, Mardulce y Entropía)

${ }^{24}$ En un artículo antes citado (Riveiro, 2019), trabajo las novedosas formas que adoptan las trayectorias editoriales de diversos escritores argentinos desde los años noventa y cómo valoran a los sectores emergentes del campo editorial sin descartar como posibilidad la publicación en editoriales de grupos transnacionales.

${ }^{25}$ Cabe aclarar que los lazos entre las editoriales grandes y las pequeñas no son inexistentes, pero sí desiguales. Las grandes editoriales, por un lado, "compran los derechos de los autores argentinos canonizados en el pasado o prestigiados internacionalmente, sea por la crítica académica o el periodismo cultural" y, si bien no apuestan a inéditos tampoco son ajenos a las nuevas corrientes literarias, buscan "absorber a los nuevos autores o editores que realizaron sus primeras publicaciones en editoriales literarias independientes, en base a contratos que, aunque magros dadas las dimensiones del mercado, éstas no pueden afrontar" (Vanoli y Saferstein, 2010, p. 78).
} 
"ocupándose asimismo de [...] formar toda una generación de latinoamericanistas" (Sancholuz, 2013, p. 2). Consultan a su profesora que, además cuenta con su experiencia en el Centro Editor de América Latina. De hecho, publica La luz argentina de Aira en 1983 en esa editorial. ${ }^{26}$

Es Zanetti quien las contacta con Aira en un momento en que él vuelve a publicar tras un período de dedicarse a los inéditos de Osvaldo Lamborghini y al Diccionario de autores latinoamericanos (también les recomienda contactarse con Alberto Laiseca que tiene unos ensayos sobre el plagio). ${ }^{27}$ Se encuentran con Aira en Buenos Aires. Aira les ofrece publicar las clases sobre Copi que da en el Centro Cultural Ricardo Rojas -ellas asisten al ciclo llamado Cómo leer a, pero no a las clases de Aira sino a las de Piglia. Cuando lo conocen le llevan la revista Paradoxa. Posiblemente el número 4/5 de 1990, que tiene un artículo de Contreras sobre El vestido rosa ("El artesano de la fragilidad") y uno de Alberto Giordano sobre Una novela china ("Digresiones sobre el amor"), sea lo primero que Aira lee sobre su obra como un conjunto producido por la academia. Con los ensayos de Aira, Copi, y de Laiseca, Por favor, iplágienme!, abre la editorial Beatriz Viterbo en 1991.

También conversan con Ricardo Piglia quien les recomienda optar por Emma Sunz para el nombre de la editorial. Pero más importante es su sugerencia de iniciar

una línea editorial que las grandes casas no cubrían -y siguen sin cubrir- y que, sin duda, es fundamental para dinamizar la vida universitaria, académica, argentina: los libros que recogen las tesis doctorales, las investigaciones individuales y las investigaciones grupales de los críticos -en su mayoría docentes universitarios- dedicados a la literatura argentina y latinoamericana. Así abrimos las colecciones "Tesis/Ensayo" y "Estudios Culturales", y más tarde la colección "Ensayos críticos" (Astutti y Contreras, 2001, p. 772).

"Docencia, investigación y autogestión en materia de publicaciones son prácticas de creciente retroalimentación" explica Gerbaudo (2014, p. 30). Así, por ejemplo, Beatriz Viterbo publica en 1994 las actas de un congreso que Josefina Ludmer organiza en Yale. El libro es Las culturas de fin de siglo en América Latina. Coloquio en Yale (8 y 9 de abril de 1994).

En segundo lugar, el propio trabajo como docentes universitarias e investigadoras supone un conjunto de saberes que ponen en práctica al crear Beatriz Viterbo. Sus trayectorias se ubican entre lo institucional y lo autogestivo. En una carrera como la de Letras de la Universidad de Rosario, que vive transformaciones por la apertura democrática -la reformulación de su plan de estudios, entre otras-, Contreras, Zanin y Astutti están terminando de cursar sus estudios y conocen a Giordano, quien ingresa como docente en un momento de revitalización de la carrera. Giordano será su docente tanto dentro de la institución como por fuera de ella.

Además de dar clases en el marco de la carrera, Giordano también organiza cursos por fuera de ella a donde asisten las futuras editoras. Giordano cuenta con experiencia en este tipo de práctica dado que cuando cursa la carrera como estudiante, insatisfecho con lo que le ofrecen las materias en una universidad intervenida por el gobierno dictatorial, junto con otros compañeros de la universidad (como Darío González que cursa Filosofía y Sergio Cueto, estudiante de Letras) contactan a Nicolás Rosa, quien entonces vive en Buenos Aires por la persecución que sufre en Rosario, para armar un grupo de estudio. Estos grupos de estudio, del mismo modo que los organizados en Buenos Aires, constituyen "verdaderas usinas intelectuales dedicadas a la importación de teorías y textos, a la traducción, a la enseñanza, a la formación de recursos humanos" (Gerbaudo, 2014, p. 58). Si bien lo mantienen interesado en su trabajo intelectual, no satisfacen sus dudas y voracidad por novedades teóricas por lo que en

\footnotetext{
${ }^{26}$ Aira recuerda a Zanetti, especialista en literatura latinoamericana, en la advertencia fechada en 1985 del Diccionario de autores latinoamericanos cuando le agradece a su "querida amiga por sus generosos préstamos de libros" (Aira, 2001b, p. 7).

${ }^{27}$ Tras el fallecimiento de Lamborghini en 1985, Aira, que es su amigo, se encarga de la transcripción y edición de la obra inédita de quien, además, considera su maestro (Strafacce, 2008). La primera de estas ediciones se publica en España en Ediciones del Serbal (Novelas y cuentos, 1988). Además, entre 1984 y 1985 Aira se dedica al estudio y lectura de autores latinoamericanos para la confección de lo que será el Diccionario de autores latinoamericanos. Ada Korn, de Ada Korn editora, firma un contrato por un año con Aira para que pueda abocarse a este trabajo que finaliza en 1985 pero el libro llegará a manos de los lectores recién en 2001 en una coedición con Emecé.
} 
1982 organiza un nuevo grupo de estudios con Juan Ritvo que proviene de la Psicología y la Filosofía y que cuenta con sensibilidad por lo literario.

Cuando retorna la democracia y en la facultad Giordano encuentra estudiantes también ávidos por aires renovadores y novedades, organiza encuentros y talleres que se realizan primero en su casa y, con los años, ganan en formalidad. ${ }^{28}$ La inscripción institucional en la facultad ocurre en 1996 cuando se crea el Centro de Estudios de Teoría y Crítica Literaria en un clima en el que "la explosión de centros en diferentes áreas del campo de las letras es producto de este trabajo subterráneo que encuentra por fin en la universidad de la democracia las vías para su institucionalización" (Gerbaudo, 2014, p. 43).

Los intereses que comparten se plasman en los programas de materias de la carrera de Letras y en las publicaciones que crean: Paradoxa. Literatura/Filosofía comienza a salir en 1986 y en 1991, el Boletín del Grupo de Estudios de Teoría Literaria que, en 1996 pasa a denominarse Boletín del Centro de Estudios de Teoría y Crítica Literaria cuando el grupo gana inscripción institucional en la universidad y lo empieza a publicar la Dirección de publicaciones de la Secretaría de extensión universitaria.

De este modo, las recientes egresadas de Letras se forman en la carrera y, a la vez, en grupos de estudios por fuera de ella. Trazan trayectorias institucionales como investigadoras, forman parte activa de la institucionalidad en vías de reformularse: son parte de las cátedras universitarias del nuevo plan de estudios, fundan publicaciones especializadas y crean centros de estudios inscriptos en la carrera de Letras. Resulta paradójico que esta productividad ocurra en un contexto de "des-financiamiento paulatino tanto de la investigación como de la enseñanza por parte del Estado" (Gerbaudo, 2014, p. 43). En este panorama los intelectuales encarnan la figura de investigador especialista: el "régimen de profesionalización" es el impuesto por "el modelo neoliberal" (Montaldo, 1999, p. 37). ${ }^{29}$

Si bien el clima no las acompaña, Astutti, Contreras y Zanin construyen circuitos que tensan lo prescripto por las instituciones oficiales para un investigador. Es así que fundan una editorial como Beatriz Viterbo aun cuando desde la transición democrática, y sobre todo en los noventa, "las condiciones de una relativa debilidad institucional de la universidad" se suman a una "actitud política puramente defensiva de la comunidad académica" que desincentiva "gestos activos que reinventaran esa tradición amenazada culturalmente y cada vez más políticamente, [que] generaba situaciones de descontento sordo sobre todo en el claustro de profesores" (Rubinich, 2001, p. 27 y 28). Las editoras perciben este movimiento a contramano: "una suerte de micropolítica cultural, si entendemos por micropolítica la creación de espacios transversales en el medio de los espacios que distribuyen e imponen las políticas mayores" (Astutti y Contreras, 2001, p. 773).

Frente a la debilidad institucional que obstaculiza la circulación del conocimiento producido en la universidad, al menos en formato de libros, ponen en juego prácticas autogestivas, recurren a los conocimientos que adquieren al transitar una carrera de docente y de investigador en la universidad para fundar una editorial. Un ejemplo concreto de estos conocimientos puestos en práctica es la presentación para un concurso de subsidios de la Secretaría de Cultura de la Nación, el Plan de promoción de la edición de literatura argentina. El subsidio se otorga en carácter de pago por una compra de libros realizados mediante la Conabip. Beatriz Viterbo se presenta para publicar Muerte y transfiguración de Martín Fierro de Martínez Estrada. Estas presentaciones son similares en su forma a las solicitudes por becas y subsidios a investigadores y profesores y cabe aclarar que en las universidades nacionales son

\footnotetext{
${ }_{28}^{28}$ Desde 1982 hasta 1986, Giordano coordina un grupo de estudios sobre Saussure, lingüística de la enunciación y Barthes (Gerbaudo, 2014, p. 58) al que asiste Nora Avaro, Analía Capdevila, Osvaldo Aguirre, Sandra Contreras, Adriana Astutti, Marcela Zanin y Judith Podlubne, por entonces estudiantes de Letras. Otros proyectos buscan construir el marco teórico para la lectura de literatura: El lugar de la literatura en el pensamiento filosófico de Gilles Deleuze, Las fuerzas políticas de la literatura y la crítica ideológica Puig Saer, Literal y la literatura política, El ensayo, entre otros.

${ }^{29}$ Una figura que Horacio González denomina con ironía "intelectuales becados de escritorio" (1988, p. 79) para referirse a la figura burocrática del intelectual especialista que en los años noventa encuentra como una de las salidas laborales la inscripción institucional como profesor universitario o investigador en un organismo estatal como el Consejo Nacional de Investigaciones Científicas y Técnicas.
} 
los becarios, investigadores y docentes quienes se ocupan de todos los detalles relativos a la presentación, seguimiento y cumplimientos de los requisitos institucionales de la carrera, lo que lleva a conocer detalles de la maquinaria burocrática.

En tercer y último lugar, como venimos viendo, la editorial resiste las corrientes preponderantes, lo que también se puede hallar en la propuesta de su catálogo. Fomentan una política de autor que contrasta con la preeminencia del corpus crítico del mismo modo que el foco en el ensayo muestra el acento en un género que viene perdiendo su centralidad desde los años ochenta.

El corpus crítico, las "figuraciones de lo familiar en relatos latinoamericanos con huérfanos, pongamos por caso" explica Dalmaroni (2005, p. 109), se puede entender al contrastarlo con un ejemplo de corpus de autor -"el objeto de la crítica son los textos firmados por, digamos, Jorge Luis Borges" (Dalmaroni, 2005, p. 109). Un ejemplo concreto de estos casos, relevante para este artículo, se puede visibilizar en el modo en que está organizada la materia Literatura Argentina II, que durante la transición democrática comienza a dictar Beatriz Sarlo en la Universidad de Buenos Aires. El programa propone "plantear algunas de las grandes tradiciones literarias que organizan el corpus de la literatura argentina a través de diferentes núcleos problemáticos que se fueron desarrollando" (Saítta, 2016, p. 14). Los ejes son nacionalismo y cosmopolitismo; lengua extranjera y traducción; cruces entre la cultura popular y la cultura letrada; los procesos de modernización urbana; criollismo y modernidad; vanguardia estética y vanguardia política; el rol de las instituciones, los grupos y las formaciones en el campo literario (Saítta, 2016).

En contraste con esta propuesta, Beatriz Viterbo implementa una política de autor. Abre colecciones que se ocupan por editar la obra de autores particulares: Norah Lange, Manuel Puig, Ezequiel Martínez Estrada y Aira. Es así que Aira puede publicar una variedad de libros en una misma editorial: ensayos (Copi, Alejandra Pizarnik), novelas (El llanto, El volante), diarios (Fragmento de un diario en Los Alpes), relatos (La trompeta de mimbre) y teatro (El mensajero), para mencionar algunos títulos solamente. Y también, crear una colección dedicada a él permite que publique una cantidad importante de libros, aunque, de todos modos, Beatriz Viterbo no llega a absorber la cantidad total de títulos que publica Aira. La proliferación de editoriales cercanas a la posición de Beatriz Viterbo y la conformación de grupos transnacionales supone una multiplicación de espacios que Aira encuentra para publicar sus libros.

La forma que adopta el catálogo no es menor: "es el catálogo y no la mera condición de 'independiente' o de 'pequeña' lo que define el valor de una editorial" afirman Astutti y Contreras (2001, p. 769). Esta misma línea se puede rastrear en los programas y trabajo académico de las editoras. Un ejemplo claro de la construcción de un corpus de autor es el estudio de Contreras sobre Aira. Contreras defiende su tesis doctoral en 2001 sobre la literatura de Aira y adopta un esquema totalizador del autor y su obra. Quizás en la pregunta que encuentra en Aira, cómo seguir haciendo arte cuando el arte ha sido hecho, resuenen otras que se hace junto con sus compañeros sobre la posibilidad de seguir haciendo crítica y teoría literaria tras la muerte del autor. Claro que la categoría de autor que se reivindica desde Rosario no es anacrónica, ni puede tomarse de manera acrítica después de que Barthes declarara su muerte. Años después Contreras aclara que la lectura de la obra literaria desde la categoría de autor está tamizada por los aportes de Deleuze que lo entienden como una singularización del punto de vista (Contreras, 2003, p. 6). ${ }^{30}$

En este mismo sentido de resistirse a los modos imperantes de pensar y editar literatura, Beatriz Viterbo habilita espacios para el género ensayístico. Este interés también se puede rastrear en las discusiones que comparten en los grupos de estudio. Entre los interrogantes que circulan en este grupo no solo importa lo que se dice sino cómo se lo dice. Los límites entre el objeto de estudio y la producción intelectual se difuminan. Quizás estas indagaciones los

\footnotetext{
${ }^{30}$ Así, tomar a Aira como autor no supone explicar todo Aira sino leer "el cuento inventado por la ficción de Aira” (Contreras, 2003, p. 10). Contreras agrega, dando cuenta de la vitalidad de este encuentro entre sus interrogantes teóricos y la literatura de Aira: "y no voy a negar que uno de los mayores placeres del trabajo fue el de trabajar con la creencia, absoluta, sí, en ese cuento; después de todo, ¿no es maravillosa la experiencia de la creencia "total" en un relato, y la de seguir leyendo, en consecuencia?" (Contreras, 2003, p. 11).
} 
acerquen a una figura de la zona heterodoxa del campo intelectual de los años noventa como Horacio González (Pulleiro, 2015). Para González la crítica es un acto intempestivo y "lo estético vive en la 'tragedia del lenguaje' y ésta consiste en el doble obstáculo de no poder encontrar para aquél un centro que lo contenga y un más allá que lo exceda" (Podlubne, 1998, p. 112). Estas afinidades pueden explicar la publicación de varios de los trabajos de las editoras y de sus pares rosarinos en la revista que dirige González, Cuadernos de la comuna (1987-1991). ${ }^{31}$

Mientras que "en el período de la transición democrática se afirma la crisis del ensayo como método de intervención crítica" (Crespi y Orsi, 2016), para estos intelectuales el ensayo se convierte en la "alternativa al trabajo monográfico o paper de corte académico" (Luzuriaga, 2015, p. 21). Con respecto a estas posiciones divergentes, rastreo una invitación a la polémica con Sarlo en el modo en que Giordano lee a Borges como ensayista en dos textos que publica en Punto de Vista (número 40 y 70). En el primero destaca la heterogeneidad de los ensayos de Borges y la redefine con Deleuze:

Borges dice en serio, Borges dice en broma, y en la distancia que se abre entre uno y otro decir, los opuestos, como opuestos, en tanto se oponen, se comunican. 'Resonancia entre dispares' dice Deleuze. A esta incertidumbre de la enunciación, a esta inestabilidad del sentido, la lectura, complicada en el juego de la diferencia, responde afirmando lo incierto e inestable: mostrando que si se quiere fijar un enunciado (como serio o paródico), no se puede evitar que él continúe moviéndose en su lugar bajo la sospecha de que disimula un aspecto diverso (Giordano, 1991, p. 38).

Como mencionamos antes, es con los ensayos de Aira, Copi, y de Laiseca, Por favor, iplágienme!, que abre la editorial. Y con estos libros también se conforma una de las colecciones, El escribiente, dedicada a ensayos de escritores. Especificar que los autores de los ensayos son narradores y poetas es central porque varias de las colecciones de la editorial están dedicadas al ensayo. Otras colecciones dedicadas al ensayo son Tesis/ensayo que se dedica a publicar las tesis de posgrado que empiezan a proliferar con la consolidación de este nivel universitario.

De este modo, la editorial Beatriz Viterbo define novedosas prácticas editoriales que contrastan con el clima signado por la incertidumbre en que nace y que, de manera simultánea, la acerca a prácticas también atípicas, como la práctica editorial que vimos que traza Aira. En un artículo que reflexiona sobre los intelectuales, una generación que son "los 'nuevos"', durante la transición democrática, Lucas Rubinich expresa:

El clima de nuestra iniciación no es fervoroso ni mucho menos (sobran razones por supuesto), no hay 'faros' al decir de Bourdieu (Borges, pero no con la algarabía del descubrimiento), estamos inmersos en un ambiente signado por la crisis de modelos teóricos, no tenemos la certeza de un camino que nos lleve hacia el lugar porque tampoco estamos seguros del lugar. Y lo que puede ser un benévolo viento foucaultiano es también, y muchas veces desconcierto (1985, p. 44 y 45).

Esta algarabía sí parece poder rastrearse en los intelectuales de Rosario en su contacto con Aira, "era como ir a hablar con Borges" cuenta Giordano reforzando la impresión de la algarabía del descubrimiento. ${ }^{32} \mathrm{El}$ cruce de dos proyectos que parecen resistir las lógicas dominantes, como la práctica de publicación atípica de Aira y la propuesta editorial de Beatriz Viterbo, se fortalecen entre sí:

\footnotetext{
${ }^{31}$ Cuadernos de la comuna es una publicación de Puerto General San Martín, localidad santafesina, gobernada por Lorenzo Domínguez, quien pertenece a la Renovación Peronista y es cercano a González. Tiene una circulación peculiar que desborda los espacios universitarios más restringidos. Se distribuye de manera gratuita en librerías y centros de estudio de Rosario, Buenos Aires, Mendoza y Santiago del Estero (Trombetta, 2016). En esta publicación participan Astutti y Contreras con un texto sobre Don Segundo Sombra (1989). Ambas junto con Zanin publican otro artículo sobre Ángel Rama en su rol de crítico y con el foco en los vínculos entre literatura popular y culta (1990). Discuten con el sentido común de los escritores del compromiso y rescatan la apuesta de Rama por una "realidad de invenciones, de formas elaboradas, o mejor, que siguen siendo elaboradas por el imaginario popular" (Astutti, Contreras y Zanin, 1990, p. 28). Nora Avaro escribe allí sobre Arlt: "Arlt fue inventor [...] ser escritor es ser inventor, o mejor, el mayor invento de Arlt -el más original- es el mundo de su literatura" (Avaro, 1990, p. 31).

${ }^{32}$ En entrevista con la autora, 24 y 25 de julio de 2019, Rosario.
} 
Cuando comenzamos a trabajar con el catálogo de Beatriz Viterbo creíamos, y todavía creemos, en el poder inquietante, tenaz y resistente de la literatura. En la experiencia a la vez íntima e impersonal que es la experiencia de la lectura vemos todavía una posibilidad (aunque microscópica no menos absoluta) de resistencia y de libertad (Astutti y Contreras, 2001, p. 771).

\section{Reflexiones finales}

En este artículo me propuse estudiar desde la sociología el campo editorial y su vínculo con los escritores. Por eso parto de la trayectoria editorial singular de un escritor como la de Aira para preguntarme por sus condiciones de posibilidad, lo que me conduce a estudiar el campo editorial. Allí encuentro el caso de Beatriz Viterbo editora que me permite indagar en zonas emergentes del campo editorial argentino de los años noventa. Desde estas zonas se habilitan prácticas novedosas y resistentes a las corrientes hegemónicas fomentadas por las políticas neoliberales que impregnan también el ámbito académico y universitario.

A su vez, el caso de Beatriz Viterbo me permite reflexionar sobre los modos de vincularnos con la teoría. Si bien las lógicas de la academia y del mercado editorial aparecen como contrapuestas, este caso nos conduce a desafiar la fetichización de la teoría que en lugar de tomarla como herramienta para pensar de manera productiva casos específicos, la utiliza de manera mecánica soslayando los datos concretos que podemos producir. Encuentro, en consecuencia, el caso de Beatriz Viterbo que nos permite estudiar una editorial que cruza los desafíos frente a la lógica académica y editorial dominante vinculado con un caso como el de Aira que tiene presencia y es exitoso en ambos ámbitos también de una manera peculiar. Así encuentro una cierta homología entre la propuesta de Beatriz Viterbo y los modos en que nos desafía para estudiarla: fomenta espacios de "resistencia" y "libertad" como proponen sus editoras (Astutti y Contreras, 2001, p. 771) que se pueden pensar como prácticas heterodoxas para el campo editorial y el universitario y nos conducen también a repensar los modos en que, como investigadores, abordamos estos casos.

\section{Bibliografía}

AGUILAR, Anna Mónica (2012). Visibilidad en las editoriales universitarias. El encuentro con el lector. In: PRIMER COLOQUIO ARGENTINO DE ESTUDIOS SOBRE EL LIBRO Y LA EDICIÓN, La Plata, 31 oct. a 2 nov. 2012. Actas [...] La Plata: Universidad Nacional de La Plata. Disponible en: http://bit.ly/2Qfnghd Acceso: 15 marzo 2020.

AIRA, César (1987). Un amor en China y la literatura portátil. [Entrevista a] María Esther Vázquez. La nación, Sección 4, p. 2, 6 jun.

AIRA, César (1991a). El sultán. Paradoxa. Literatura/Filosofía, Rosario, n. 6.

AIRA, César (1991b). Todo escritor inventa su idioma. César Aira: literatura y paradojas. [Entrevista concedida a] Hinde Pomeraniec. Clarín, Cultura y Nación, p. 1-3, 27 jun.

AIRA, César (1993a). Arlt. Paradoxa. Literatura/Filosofía, Rosario, n. 7.

AIRA, César (1993b). Exotismo. Boletín. Grupo de Estudios de Teoría Literaria, Rosario, n. 3.

AIRA, César (1994a). La innovación. Boletín. Grupo de Estudios de Teoría Literaria, Rosario, n. 4.

AIRA, César (1994b). Sobre una novela de Tanizaki. Tokonoma. Traducción y literatura, Buenos Aires, n. 2.

AIRA, César (1994c). Ars narrativa. Criterion, Caracas, n. 8.

AIRA, César (1995). Sobre una novela de Walter de la Mare. Tokonoma. Traducción y literatura, Buenos Aires, n. 3.

AIRA, César (1997). El último escritor. El banquete (revista anual de literatura), Córdoba, n. 1.

AIRA, César (1999). Kafka, Duchamp. Tigre. Travaux des hispanistes de l'Université Stendha, Grenoble, n. 10.

AIRA, César (2001a). El ensayo y su tema. Boletín. Grupo de estudios de Teoría Literaria, Rosario, n. 9. 
AIRA, César (2001b). Diccionario de autores latinoamericanos. Buenos Aires: Emecé y Ada Korn.

AIRA, César (2001c). Quisiera ser un salvaje. [Entrevista a] Eduardo Berti. 3 puntos, v. 5, n. 227, p. 62-63.

AIRA, César (2001d). ¿Aira es Dios? [Entrevista a] Emilio Fernández Cicco. Noticias, p. 50-53, 4 ago.

AIRA, César (2004). Prefiero siempre lo nuevo a lo bueno. [Entrevista a] Raquel Garzón. El país, Cultura, 18 abr. Disponible en: http://elpais.com/diario/2004/04/18/cultura/1082239201_850215.html. Acceso: 13 mayo 2019.

AIRA, César (2005). El artista puede ser un criminal. [Entrevista a] Xavi Aiyén. La nación, 27 jun. Disponible en: https:/ / bit.ly/3c1YGsF. Acceso: 13 mayo 2019.

AIRA, César (2009). César Aira by María Moreno. [Entrevista concedida a] María Moreno. M. Bomb Magazine, n. 109. Disponible en: https:/ / bombmagazine.org/articles/c\%C3\%A9sar-aira/. Acceso: 13 mayo 2019.

AIRA, César (2017). César Aira: No se puede ser escritor y ser importante al mismo tiempo, hay que elegir una de las dos cosas. [Entrevista concedida a] Francisco Marzioni. Infobae, 17 sep. Disponible en: http:/ / bit.ly/3lyqQyN. Acceso: 13 mayo 2019.

AIRA, César. [Entrevista concedida a] María Belén Riveiro. 5 mayo 2017. Ciudad Autónoma de Buenos Aires.

ASTUTTI, Adriana (1997). Un niño en la biblioteca nacional. Revista de Letras, n. 5, p. 37-43.

ASTUTTI, Adriana; CONTRERAS, Sandra (1989). Don Segundo Sombra: el oficio de mirar. Cuadernos de la Comuna, n. 22, p. 23-26.

ASTUTTI, Adriana; CONTRERAS, Sandra (2001). Editoriales independientes, pequeñas... Micropolíticas culturales en la literatura argentina actual. Revista Iberoamericana, v. 67, n. 197, p. 767-780.

ASTUTTI, Adriana; CONTRERAS, Sandra; ZANIN, Marcela (1990). Ángel Rama: edificación de una literatura popular para América Latina. Cuadernos de la Comuna, n. 25, p. 25-29.

AVARO, Nora (1990). Cumplir con Roberto Arlt. Cuadernos de la Comuna, n. 25, p. 30-31.

AVARO, Nora. [Entrevista concedida a] María Belén Riveiro. 25 julio 2019. Rosario.

AZPIAZU, Daniel; MANZANELLI, Pablo; SCHORR, Martín (2011). Concentración y extranjerización. La Argentina en la posconvertibilidad. Buenos Aires: Capital Intelectual.

BEMBIBRE, Cecilia (1999). El método de la Contraferia permanente. Página/12, Radar libros, 5 marzo 1999. Disponible en: https:/ / www.pagina12.com.ar/1999/99-03/99-03-05/pag25.htm. Acceso: 9 marzo 2018.

BORGES dijo ser un escritor sin herederos (1983). Convicción, p. 24, 2 ago.

BORGES, Jorge Luis (1982). Somos un país más bien desdichado. Cultura y Nación. Clarín, p. 2-3, 25 feb.

BOTTO, Malena (2014). 1990-2010. Concentración, polarización y después. In: LUIS DE DIEGO, José (Dir.). Editores y políticas editoriales en Argentina (1880-2010). Buenos Aires: Fondo de Cultura Económica. p. 219-269.

BOURDIEU, Pierre (2000). Intelectuales, política y poder. Buenos Aires: Eudeba.

BOURDIEU, Pierre (2005). Las reglas del arte. Génesis y estructura del campo literario. Barcelona: Anagrama.

BOURDIEU, Pierre (2007). El sentido práctico. Buenos Aires: Siglo XXI.

BOURDIEU, Pierre; WACQUANT, Loic J. D. (1995). Respuestas: por una antropología reflexiva. México: Grijalbo.

BUQUETE, Ignacio (2001). Las editoriales independientes ya no miran la Feria desde afuera. La nación, p. 10,25 abr.

CANTAMUTTO, Francisco J.; WAINER, Andrés (2013). Economía política de la convertibilidad. Disputa de intereses y cambio de régimen. Buenos Aires: Capital Intelectual.

CENTENO, Rafael (2012). Circulación y fronteras comerciales del libro universitario. In: PRIMER COLOQUIO ARGENTINO DE ESTUDIOS SOBRE EL LIBRO Y LA EDICIÓN, La Plata, 31 oct. a 2 nov. 2012. Acta [...]. La Plata: Universidad Nacional de La Plata. Disponible en: https://bit.ly/3eZwkRK. Acceso: 10 marzo 2020.

CONTRERAS, Sandra (2002). Las vueltas de César Aira. Rosario: Beatriz Viterbo. 
CONTRERAS, Sandra (2003). Intervención. Boletín/11 del Centro de Estudios de Teoría y Crítica Literaria, n. 11, p. 1-13.

CONTRERAS, Sandra. [Entrevista concedida a] María Belén Riveiro. 22 julio 2019. Rosario.

COSTA, Flavia; GAZZERA, Claudio (2013). Políticas editoriales y universidades públicas. Los desafíos de la cultura. Voces del Fénix, La revista del Plan Fénix, v. 4, n. 29, p. 115-121. Disponible en https://bit.ly/3r8oyaF. Acceso: 20 marzo 2020.

COSTA, Flavia; SAGASTIZÁBAL, Leandro de (2016). Las editoriales universitarias: los caminos de la profesionalización. Anuario del Centro de Estudios Económicos de la Empresa y el Desarrollo, v. 8, n. 8, p. 157182. Disponible en ojs.econ.uba.ar/ojs/index.php/CEEED/. Acceso: 20 marzo 2020.

CRESPI, Maximiliano; GARCÍA ORSI, Ana (2016). Lugares en conflicto: la crítica y el ensayo como escrituras de la lectura. El matadero, n. 10, p. 41-50.

DALMARONI, Miguel (2005). Historia literaria y corpus crítico (aproximaciones williamsianas y un caso argentino). Boletín/12 del Centro de Estudios de Teoría y Crítica Literaria, n. 12, p. 109-128. Disponible en: https://www.cetycli.org/cboletines/dalmaroni_b_12.pdf. Acceso: 15 dic. 2019.

DALMARONI, Miguel (2010). El largo camino del "silencio" al "consenso". La recepción de Saer en la Argentina (1964-1987). In: SAER, Juan José. Glosa. El entenado. Edición crítica. Coordinación de Julio Premat. Poitiers: Université de Poitiers. Córdoba: Alción. p. 607-663.

DIEGO, José Luis de (2010). Un itinerario crítico sobre el mercado editorial de literatura en Argentina. Iberoamericana, v. X, n. 40, p. 47-62.

DIEGO, José Luis de (2012). Concentración económica, nuevos editores, nuevos agentes. In: PRIMER COLOQUIO ARGENTINO DE ESTUDIOS SOBRE EL LIBRO Y LA EDICIÓN, La Plata, 31 oct. a 2 nov. 2012. Acta [...] La Plata: Universidad Nacional de La Plata. Disponible en: https://bit.ly/3lB7BEG. Acceso: 7 marzo 2020.

DUJOVNE, Alejandro (2020). Gutenberg atiende en Buenos Aires. La edición universitaria ante la concentración geográfica del mercado editorial argentino. Cuaderno 85 - Centro de Estudios en Diseño y Comunicación (2019/2020), n. XXI, p. 35-47. Disponible en: https:/ / bit.ly/3s8LDv1. Acceso: 27 marzo 2020.

ESTRÍN, Laura (1999). César Aira: el realismo y sus extremos. Buenos Aires: Ediciones del Valle.

FAISÁN-AUTOR (1982). El porteño, v. I, n. 1, p. 25.

FERNÁNDEZ MOYA, María (2011). La internacionalización del sector editorial español (1898-2010). In: CONGRESO INTERNACIONAL DE LA ASOCIACIÓN ESPAÑOLA DE HISTORIA ECONÓMICA, 10., 2011, Universidad Pablo de Olavide Carmona, Sevilla.

FERNÁNDEZ, Nancy (2000). Narraciones viajeras. César Aira y Juan José Saer. Buenos Aires: Biblos.

FERNÁNDEZ, Nancy (2005). Escrituras de lo real: César Aira y Arturo Carrera. Tesis (Doctorado en Letras) - Universidad Nacional de La Plata, La Plata.

GARCÍA, Mariano (2006). Degeneraciones textuales. Los géneros en la obra de César Aira. Rosario: Beatriz Viterbo.

GERBAUDO, Analía (2014). Primer informe técnico: la institucionalización de las letras en la universidad argentina 1945-2010. Notas en borrador a partir de un relevamiento. Santa Fe: Universidad Nacional del Litoral. Disponible en http:/ / www.fhuc.unl.edu.ar/centros/cedintel/interco_vf.pdf Acceso: 27 marzo 2020.

GIORDANO, Alberto (1991). Borges: la forma del ensayo. Punto de Vista, n. 40, p. 32-40.

GIORDANO, Alberto. [Entrevista concedida a] María Belén Riveiro. 24 y 25 julio 2019. Rosario.

GONZÁLEZ, Horacio (1988). De Lugones a Portantiero. El porteño, n. 75, p. 77-79.

HOPENHAYN, Silvia. (1998). Casi todo está permitido. La nación, Cultura, p. 6, 10 mayo.

HUTNIK, Elizabeth (2013). La industria editorial argentina en el siglo XXI: los desafíos de las nuevas tecnologías en la producción y la recepción. Tesis (Doctorado en Ciencias Sociales) - Universidad de Buenos Aires, Buenos Aires. v. 1

IDEZ, Ariel (2011). La última de César Aira. Buenos Aires: Pánico el pánico. 
KORN, Ada. [Entrevista concedida a] María Belén Riveiro. 15 enero 2018. Ciudad Autónoma de Buenos Aires.

LADDAGA, Reinaldo (2001). Una literatura de la clase media: notas sobre César Aira. Hispamérica, n. 88.

LINK, Daniel (2003). Cómo se lee y otras intervenciones críticas. Buenos Aires: Norma.

LUZURIAGA, Pablo (2015). El Ojo Mocho: “una sociología quizás artística”. El matadero, n. 9, p. 17-31.

MARTÍNEZ, Ana Teresa (2007). Pierre Bourdieu: razones y lecciones de una práctica sociológica. Del estructuralismo genético a la sociología reflexiva. Buenos Aires: Manantial.

MATTONI, Silvio (2003). César Aira. Una introducción. In: ARÁN, Pampa Olga et al. Umbrales y catástrofes: literatura argentina de los ‘90. Córdoba: Epoké.

MIHAL, Ivana; SZPILBARG, Daniela (2018). Editoras universitárias, livros digitais e bibliotecas populares na gestão da Conabip na Argentina. Memória e Informação, v. II, n. 2, p. 1-19.

MONTALDO Graciela (1990). Un argumento contraborgiano en la literatura argentina de los años 80 (Sobre C. Aira, A. Laiseca y Copi), Hispamerica, n. 55, p. 105-12.

MONTALDO, Graciela (1998). Borges, Aira y la literatura para multitudes. Boletín/6, Rosario, n. 6, p. 7-17.

MONTALDO, Graciela (1999). Intelectuales y artistas en la sociedad civil argentina en el fin de siglo. Maryland: University of Maryland. (Working Paper, 4)

MORENO, María (2001). El lugar de la resistencia. Radar libros. Página/12. Disponible en: https://www.pagina12.com.ar/2001/suple/Libros/01-10/01-10-07/nota1.htm. Acceso: 15 jun. 2019.

MUNIZ JÚNIOR, José de Souza (2015). Itinerarios de una identidad voluble: el debate sobre la edición "independiente" en Francia y Brasil. Orbis Tertius, v. 20, n. 21, p. 145-158. Disponible en: http://www.memoria.fahce.unlp.edu.ar/art_revistas/pr.6853/pr.6853.pdf. Acceso: 2 marzo 2020.

PODLUBNE, Judith (1998). El pensamiento de la crítica (Beatriz Sarlo y Horacio González). Boletín/6 del centro de Estudios de Teoría y Crítica Literaria, n. 6, p. 99-117.

PULLEIRO, Adrián (2015). Un llamado a la disidencia. La construcción de una posición intelectual heterodoxa en el surgimiento de El ojo mocho (1991-1994). In: JORNADAS DE SOCIOLOGÍA DE LA UBA, 11., 2015, Universidad de Buenos Aires, Buenos Aires.

REMON-RAILLARD, Margarita (1999). César Aira o la literatura del continuo. Tesis (Doctorado en Estudios de Romance) - Université Stendhal Grenoble 3, Gières.

RIVEIRO, María Belén (2018). Trayectorias editoriales inversas: escritores argentinos de narrativa entre fines del siglo XX y comienzos del siglo XX. Badebec, v. 8, n. 15, p. 155-178. Disponible en: http:// bit.ly/3s8gp7wAcceso: 15 mayo 2019.

RIVEIRO, María Belén (2019). César Aira en entrevistas: la construcción de la figura de escritor (19812001), Trabajo y Sociedad, v. XX, n. 33, p. 83-101. Disponible en https://bit.ly/3c3EG8Y Acceso: 10 dic. 2019.

RIVEIRO, María Belén (2020). La trayectoria de César Aira: la conformación de un centro descentrado en el campo literario de la ciudad de Buenos Aires (1981-2001). Tesis (Doctorado en Ciencias Sociales) Universidad de Buenos Aires, Buenos Aires.

RUBINICH, Lucas (1985). Retrato de una generación ausente. Punto de vista. Revista de cultura, v. 7, n. 23, p. 44-46.

RUBINICH, Lucas (2001). La conformación de un clima cultural. Neoliberalismo y universidad. Buenos Aires: Libros del Rojas.

SAFERSTEIN, Ezequiel; SZPILBARG, Daniela (2012). El espacio editorial "independiente": heterogeneidad, Posicionamientos y debates. Hacia una tipología de Las editoriales en el período 19982010. In: PRIMER COLOQUIO ARGENTINO DE ESTUDIOS SOBRE EL LIBRO Y LA EDICIÓN, La Plata, 31 oct. a 2 nov. 2012. Actas [...] La Plata: Universidad Nacional de La Plata. p. 464-484. Disponible en: http:// bit.ly/3s6jODT. Acceso: 30 oct. 2019.

SAGASTIZÁBAL, Leandro de (2002). Informe sobre la situación y perspectivas de las editoriales universitarias en Argentina. Buenos Aires: Iesalc/Unesco. 
SAGASTIZÁBAL, Leandro de; RAMA, Claudio; URIBE, Richard (2006). Las editoriales universitarias en América Latina. Venezuela: Iesalc; Cerlalc.

SAGASTIZÁBAL, Leandro de; VEGA, Ramiro (2013). La gestión económica en la editorial universitaria. Santa Fe: Ediciones de la Universidad Nacional del Litoral.

SAÍTTA, Sylvia (2016). En torno a los cien años de la cátedra de Literatura Argentina en la Universidad de Buenos Aires. Cuadernos del Sur, n. 43, p. 221-233.

SANCHOLUZ, Carolina (2013). Susana Zanetti en el recuerdo: semblanzas. Orbis Tertius, v. 18, n. 19, p. 12. Disponible en: https:// bit.ly/3cLeoHG Acceso: 14 ene. 2019.

SPERANZA, Graciela (2001). César Aira. Manual de uso. Milpalabras. Letras y artes en revista, n. 1, p. 2-13.

STRAFACCE, Ricardo (2008). Osvaldo Lamborghini: una biografía. Buenos Aires: Mansalva.

STRAFACCE, Ricardo (2018). César Aira: un catálogo. Buenos Aires: Mansalva.

SZPILBARG, Daniela (2019). Cartografía argentina de la edición mundializada. Modos de hacer y pensar el libro en el siglo XXI. Buenos Aires: Tren en Movimiento.

TROMBETTA, Sofía (2016). La intelectualidad argentina post-dictadura. El caso de los Cuadernos De La Comuna. Andes. Antropología e Historia, n. 27, p. 1-20. Disponible en: https:/ / bit.ly/3s1Hn0t. Acceso: 10 mayo 2019.

VANOLI, Hernán (2009). Pequeñas editoriales y transformaciones en la cultura literaria Argentina. Apuntes de investigación, n. 15, p. 161-185. Disponible en: http:// bit.ly/3s6VVf7. Acceso: 20 ene. 2019.

VANOLI, Hernán (2010). Por una sociología del espacio editorial. Cuatro modelos de edición literaria en la Argentina del siglo XX. Tesis (Doctorado en Ciencias Sociales) - Universidad de Buenos Aires, Buenos Aires.

VANOLI, Hernán; SAFERSTEIN, Ezequiel (2011). Cultura literaria e industria editorial. Desencuentros, convergencias y preguntas alrededor de la escena de las pequeñas editoriales. In: RUBINICH, Lucas; MIGUEL, Paula (Ed.). Creatividad, economía y cultura en la ciudad de Buenos Aires 2001-2010. Buenos Aires. Aurelia Rivera.

ZANIN, Marcela. [Entrevista concedida a] María Belén Riveiro. 23 julio 2019. Rosario.

\section{Reconocimiento}

Agradezco al Consejo Nacional de Investigaciones Científicas y Técnicas (Conicet) por otorgarme la beca doctoral que financió la investigación de la que resulta la tesis doctoral en la que se inscribe este trabajo. También quiero agradecer a los directores de la tesis, Lucas Rubinich y Daniela Lucena, cuya guía es fundamental, y a los entrevistados, cuya generosidad es valiosa y central para el presente análisis.

\section{Nota}

El presente artículo se desprende de mi tesis doctoral (2020) titulada La trayectoria de César Aira: la conformación de un centro descentrado en el campo literario de la ciudad de Buenos Aires (1981-2001) Doctorado en Ciencias Sociales, Facultad de Ciencias Sociales, Universidad de Buenos Aires. 